\title{
Bioética e saúde global a partir de baixo: - global a partir da realidade local
}

\author{
Bioethics and global health from below: \\ the global from the local reality
}

Alexandre Andrade Martins

\section{Resumo}

Saúde global é uma área interdisciplinar que se expandiu muito nas últimas duas décadas e, com ela, muitas questões éticas sugiram. Contudo, a bioética, especialmente a produzida no Brasil, não acompanha os desafios de saúde global no mesmo ritmo que eles aparecem. O principal foco dos debates da bioética global é sobre sua legitimidade e seus métodos. Com a pandemia de Covid-19, claramente um problema de saúde global, a relação entre o local e o global foi explicitada, apresentado questões éticas difíceis de serem negadas por bioeticistas. Este artigo apresenta uma reflexão sobre saúde global e a necessidade de uma bioética que enfrente as questões éticas provenientes das relações entre o global e o local. Para isso, a tese desenvolvida é de uma bioética a partir de baixo, em vista de compreender as questões de saúde global a partir da perspectiva da realidade local e capaz de incluir as vozes das pessoas pobres e marginalizadas. Os princípios de subsidiariedade e de opção preferencial pelos pobres são apresentados como recursos para o desenvolvimento dessa bioética a partir de baixo no campo da saúde global.

Palavras-chave: Saúde global. Bioética global. Covid-19. Subsidiariedade. Opção pelos pobres. 


\begin{abstract}
Global health is an interdisciplinary field that has expanded a lot in the last two decades and many ethical issues were raised with this expansion. However, bioethics, especially the studies developed in Brazil, has not addressed global health challenges at the same pace as they appear. The main focus of global bioethics discussion is on its legitimacy and method. With the Covid-19 pandemic, a clearly global health problem, the relationship between the local and the global became explicit, presenting ethical issues that bioethicists cannot deny. This article examines global health and the need for a bioethics that addresses the ethical issues raised by the relationship between the global and the local. For this, this essay argues for the development of a bioethics from below in order to understand global health issues from the perspective of the local reality capable of including the voices of the poor and marginalized. Catholic social teaching of subsidiarity and the preferential options for the poor are present as resources for the development of this bioethics from below in the field of global health.
\end{abstract}

Keywords: Global health. Global bioethics. Covid-19. Subsidiarity. Option for the poor.

\title{
Introdução
}

Nas últimas duas décadas, vimos a construção e expansão de um novo campo interdisciplinar de ação e estudos conhecido como saúde global, liderado particularmente por países do hemisfério norte. No Brasil, esse campo ainda atrai pouca atenção de pesquisadores, professionais da saúde, pensadores e líderes políticos. No aspecto prático da saúde global, o Brasil tem pouca - ou quase nenhuma - tradição em ajudar outros países nas questões relativas à saúde, seja essa ajuda por meio de parcerias internacionais entre governos ${ }^{1}$ ou por meio das ações de organizações não governamentais brasileiras na área da saúde atuando em outros países. É fato que os brasileiros têm voluntariado

\footnotetext{
${ }^{1}$ Um exemplo de saúde internacional, no caso o Brasil recebendo ajuda, foi o Programa Mais Médicos, sendo a parceria mais conhecida a estabelecida entre os governos brasileiro e cubano. JESUS, R. A. de; MEDINA, M. G.; PRADO, N. M. de B. L., Programa Mais Médicos, p. 1241-1256.
} 
em ações internacionais de saúde, como as promovidas pelos Médicos sem Fronteiras, assim como o Brasil conta com a presença de organizações internacionais atuando no país, além de organizações brasileiras com projetos de assistência à saúde financiados por recursos estrangeiros.

Quando olhamos especificamente para a bioética, percebemos que há uma limitada produção dessa disciplina orientada à saúde global. Há poucos estudos bioéticos no Brasil abordando questões de saúde global, uma área ainda a ser explorada. Existem produções mais robustas na área de bioética global, mas com estudos voltados à bioética em si mesma, em torno de um debate sobre a possiblidade ou a negação de uma bioética global a partir de princípios de caráter universal. As teses sobre a legitimidade ou não de uma bioética global, apresentadas no Brasil, seguem a discussão internacional sobre o mesmo tema, que também falha em desenvolver uma bioética que ultrapasse essa reflexão interna e se volte às questões éticas em saúde global.

Considerando estudos bioéticos de caráter teológico produzidos no Brasil, nota-se uma lacuna ainda maior em relação aos desafios da saúde global. Internacionalmente, essa perspectiva a partir da Teologia também é muito tímida, apesar de existir trabalhos como o organizado pelos teólogos estadunidenses da Universidade Loyola de Chicago, M. Therese Lysaught e Michael McCarthy, ${ }^{2}$ Catholic Bioethics \& Social Justice: The Praxis of US Health Care in a Globalized World, e o do Paul Farmer que, apesar de não ser um teólogo, mas um médico antropologista, utiliza-se da Teologia da Libertação como fundamento para sua reflexão e ação no campo da saúde global. ${ }^{3}$ Ele chegou até a escrever um livro com o teólogo peruano Gustavo Gutiérrez sobre a importância do princípio da ética social católica, conhecido como opção preferencial pelos pobres, à saúde global. ${ }^{4}$ Por fim, temos o trabalho de Alexandre A. Martins com uma reflexão bioética em diálogo com a Teologia sobre os desafios éticos em saúde global. ${ }^{5}$

O caráter da legitimidade de conceitos universais para uma bioética global domina o debate. Trabalhos que exemplificam isso são o de Tristam Engelhardt e sua bioética ortodoxa, que refuta a possibilidade de uma bioética

\footnotetext{
${ }^{2}$ LYSAUGHT, M. T.; McCarthy, M. (Orgs.)., Catholic Bioethics \& Social Justice.

${ }^{3}$ Um dos principais trabalhos do Paul Farmer foi traduzido no Brasil: FARMER, P., Patologias do poder.

${ }^{4}$ FARMER, P.; GUTIÉRREZ, G., In the company of the poor.

${ }^{5}$ MARTINS, A. A., The Cry of Poor.
} 
global, ${ }^{6}$ e o de Henk Ten Have, que acredita que a bioética global não é apenas possível como necessária. ${ }^{7}$ No Brasil, talvez o bioeticista e teólogo Léo Pessini seja um dos que mais se dedicou à bioética global, especialmente em seus últimos anos de vida. Pessini acreditava na importância de uma bioética global, de caráter plural, inclusiva e orientada à vida dos pobres. Encontrou na vulnerabilidade ${ }^{8}$ o elemento que permitiria essa conexão transnacional para os direitos humanos e a bioética global: “A questão dos direitos humanos está profundamente conectada ao conceito de vulnerabilidade, mas também ao desenvolvimento da bioética global". ${ }^{9}$ Contudo, essa bioética global aborda apenas questões de saúde global de forma tangencial, carecendo de uma perspectiva que não seja sobre si mesma, mas sobre os desafios éticos da saúde global.

$\mathrm{Na}$ América Latina, a bioética - que foi introduzida na região a partir da bioética originada nos EUA, com foco nas questões biomédicas, especialmente os conflitos na relação médico-paciente - logo se envolveu com as questões sociais em torno da saúde, em um contexto marcado pela pobreza e por desigualdades, com os maiores desafios no acesso a serviços médicos. Dessa forma, a bioética aqui assumiu prontamente um caráter social e libertador, com perspectivas como a bioética de intervenção, articulada primeiramente por Volnei Garrafa e Dora Porto, ${ }^{10}$ e a bioética de matriz libertadora, da qual os teólogos Márcio Fabri dos Anjos ${ }^{11}$ e Christian de Paul Barchifontaine $^{12}$ foram pioneiros. Fala-se agora também de uma bioética com foco no enfrentamento das estruturas e das interações históricas, econômicas e socioculturais que criam e sustentam relações de exploração e dominação. ${ }^{13}$ Esse aspecto social, orientado às questões de saúde decorrente da injustiça, fez com que a bioética no Brasil, tanto de matriz secular quanto teológica, se aproximasse da área de saúde pública, enfrentado questões

\footnotetext{
${ }^{6}$ ENGELHARDT, H. T., Global Bioethics, p. 1-17.

${ }^{7}$ TEN HAVE, H., Global Bioethics.

${ }^{8}$ Vulnerabilidade como elemento catalizador de uma bioética de abrangência global em vista da promoção dos direitos humanos é também a perspectiva presente na UNESCO, Declaração Universal sobre Bioética e Direitos Humanos. Sobre esse conceito de vulnerabilidade na bioética global, veja: CUNHA, T.; GARRAFA, V., Vulnerability, p. 197-208.

${ }_{9}^{9}$ PESSINI, L., Bioética global, vulnerabilidade e agenda 2030 da ONU, p. 439.

${ }^{10}$ GARRAFA, V.; PORTO, D., Bioética, poder e injustiça, p. 37-45.

${ }^{11}$ ANJOS, M. F. dos., Bioética em perspectiva de libertação, p. 455-465.

${ }^{12}$ BARCHIFONTAINE, C. P., Saúde pública é bioética?

${ }^{13}$ CUNHA, T.; LORENZO, C., Bioética global na perspectiva da bioética crítica, p. 116-125.
} 
como as desigualdades em saúde, a necessidade de políticas com base na equidade e os determinantes sociais de saúde. ${ }^{14}$

Se, por um lado, a bioética no Brasil voltou-se às questões de saúde pública, com uma produção robusta e relevante, por outro, a expansão para o campo da saúde global - e até mesmo o perceber das relações entre o local e o global na área da saúde - não seguiu a mesma linha. Com a chegada da pandemia de Covid-19, claramente um problema de saúde global até mesmo para os mais isolados e alheios a qualquer preocupação com serviços de saúde que ultrapassem a própria necessidade pessoal, a relação entre o local e o global tornou praticamente impossível para os bioeticistas contornarem esse elefante no meio da sala sem vê ou tocá-lo. A pandemia tornou urgente a necessidade de uma bioética que deixe de discutir a si mesma sobre a legitimidade de uma vertente com princípios universais, e que enfrente, como bioética, as questões éticas de saúde global. Dessa forma, a pandemia de Covid-19 está desafiando a bioética a se debruçar sobre as questões de saúde global, com estudos sobre as relações entre o global e o local no campo da saúde a partir do impacto na experiência das pessoas na realidade local. De modo introdutório, este texto tece uma contribuição, somando-se a outras já sendo publicadas pelo mundo, ${ }^{15}$ para enfrentar esse desafio. Partiremos do que já foi construído até aqui, pois esses são os recursos disponíveis para podermos avançar e, assim, oferecermos algo para a busca de respostas aos desafios éticos relacionados à saúde global, agora expostos e/ou exacerbados pela pandemia de Covid-19. Primeiramente será apresentado o que se entende como saúde global, essa que está sendo corroída pela pandemia. Em seguida, desenvolveremos uma reflexão partindo da tese que a compreensão das questões de saúde global necessita, de uma perspectiva da realidade local que inclua as vozes e a participação das pessoas pobres e marginalizadas, pois elas têm algo para contribuir a partir de seu conhecimento experiencial - são elas que vivem as dores e os sofrimentos

\footnotetext{
${ }^{14}$ Trabalhos pioneiros de bioética e saúde pública são: FORTES, P. A. de C.; ZOBOLI, E. L. (Orgs.)., Bioética e saúde pública. BARCHIFONTAINE, C. P. ; ZOBOLI, E. (Orgs.)., Bioética, vulnerabilidade e saúde.

${ }^{15}$ Muitos textos sobre bioética e saúde global, especialmente relacionados com a pandemia, têm sido publicados internacionalmente. Por exemplo, The American Journal of Bioethics dedicou toda a edição de junho de 2020 (v. 20, n. 07) a questões bioéticas decorrentes da pandemia de Covid-19. Há também o periódico internacional Global Bioethics, que se dedica às questões globais. No Brasil, essa produção segue a mesma intensidade, como mencionamos na introdução deste artigo, mas algumas produções começam a aparecer, como: NOHAMA, N.; DA SILVA, J. S.; SIMÃO-SILVA, D., Desafios e conflitos bioéticos da covid-19, p. 585-594.
} 
das injustiças em saúde na realidade local. Mostraremos a contribuição da chamada opção preferencial pelos pobres para o desenvolvimento dessa bioética em saúde global a partir de baixo.

\section{Bioética e Saúde Global}

O debate sobre a legitimidade de uma bioética global busca responder à questão se há valores universais capazes de proporcionar um referencial bioético que transpasse as particularidades culturais dos países em um mundo globalizado. Ela tem uma preocupação global com o desenvolvimento das ciências da vida e com a sobrevivência e a manutenção de um planeta sustentavelmente habitável. Sendo assim, a saúde global parece uma preocupação natural para aqueles que reconhecem a necessidade de uma bioética global. Se, por um lado, a universalidade dos referenciais bioéticos é matéria de dissenso, por outro, o fenômeno da globalização tem um impacto no mundo da saúde, e os desafios que isso gera para as realidades locais, em sua relação com o global (ou com o internacional), mostram problemas objetivos que precisam ser enfrentados. A pandemia de Covid-19 tem essa objetividade que nenhum dissenso sobre a universalidade de conceitos e princípios consegue negar. Nesse sentido, a proposta é uma bioética que parta da realidade objetiva, isto é, dos problemas concretos que impactam o mundo da saúde e objetivamente vulnerabilizam, adoecem e matam pessoas. Esse partir da realidade permite um ponto de encontro entre as mais diversas visões de mundo e culturas, onde o diálogo se torna uma ferramenta para que diferentes sujeitos se engajem na busca por caminhos para enfrentar questões concretas, que tocam a saúde e a vida das pessoas. Portanto, ver a realidade da saúde global - conhecer as questões pontuais no ambiente local e sua relação com o global, sentir e se solidarizar com as pessoas que estão sofrendo, estar com elas, contemplar suas faces e escutar suas vozes - cria caminhos para o encontro entre diferentes sujeitos, capazes de dialogar sobre os desafios objetivos que precisam ser enfrentados por uma bioética voltada à saúde global. ${ }^{16}$ Essa perspectiva muda o foco do debate de uma busca (ou negação)

\footnotetext{
${ }^{16}$ Essa perspectiva do iniciar da realidade, junto com as pessoas que melhor representam os problemas enfrentados no contexto da saúde, tem sua base na perspectiva teológica na qual a realidade dos pobres se torna o locus de onde se realiza a reflexão teológica. Dessa forma, a sugestão é de uma bioética que torna a realidade e o encontro com as pessoas que sofrem, devido a marginalização socioeconômica que as torna mais vulneráveis a enfermidades (e,
} 
de referenciais universais para uma bioética global, realizada de cima para baixo, para um método que se inicia a partir do olhar e do compreender a realidade onde os problemas são concretamente experienciados na vida das pessoas, onde acontece um encontro dialógico de baixo para cima.

De forma didática, a opção deste texto é por não entrar na discussão sobre uma bioética global, mas expandir a compressão do que seja saúde global e como ela está sendo fortemente ferida pela pandemia de Covid-19, o que impacta desproporcionalmente os mais pobres e os grupos tradicionalmente marginalizados em seus países - como negros e indígenas, no caso brasileiro. A saúde global é um campo novo que tem ganhado muito destaque no século XXI. Há várias definições sobre o que seria de fato saúde global como uma área de atuação. Apesar de divergências, o comum a todas as perspectivas é que a saúde global é uma área que abrange questões relacionadas à saúde, sejam elas a assistência médica ou os determinantes socioeconômicos de saúde, ultrapassando fronteiras nacionais e influenciando experiências em outros países. É uma área interdisciplinar que abrange ações de promoção de saúde e bem-estar, além de pesquisas com o objetivo de avançar a equidade em saúde de grupos sociais menos favorecidos e da população global como um todo. ${ }^{17}$ Um dos pioneiros da bioética e saúde pública no Brasil, Paulo Fortes, assim apresenta a saúde global:

Desde as últimas décadas do século passado, vem sendo construído o campo da Saúde Global, com caráter multiprofissional e interdisciplinar, envolvendo o conhecimento, o ensino, a pesquisa e a prática, enfocando questões e problemas de saúde supraterritoriais, que extrapolam as fronteiras nacionais, assim como seus determinantes e as possíveis soluções, necessitando da intervenção e de acordos entre diversos atores sociais, incluindo países e governos, agências e instituições internacionais públicas e privadas. ${ }^{18}$

Como se pode perceber, a saúde global é como uma expansão da saúde pública, essa compreendida como o conjunto de ações organizadas, em uma

quando doentes, sem acesso a assistência à saúde adequada, sendo a morte precoce o destino de muitas), o locus onde a reflexão bioética e sua interação com a assistência à saúde são realizadas. Sobre a realidade como locus teológico, veja: BOFF, L., Jesus Cristo libertador, p. 13-14. ${ }^{17}$ Algumas definições de saúde global podem ser encontradas: ABDALLA, S. M.; OGNENIS, S., Key Concepts in Global Health, p. 7-11.

${ }^{18}$ FORTES, P. A. de C., Refletindo sobre os valores éticos da saúde global, p. 154. 
sociedade, para prevenir doenças, promover e cuidar da saúde, e prolongar a vida das pessoas e o bem-estar da população em geral. ${ }^{19} \mathrm{O}$ foco da saúde pública é a saúde populacional. Esse também é o foco da saúde global quando se expande para além das fronteiras nacionais. Paul Farmer et al. afirma que a saúde global é interdisciplinar e necessita análises biossociais, em vista de compreender as injustiças e desigualdades em saúde que criam um fardo de enfermidade e mortes desproporcionais para as pessoas e os países mais pobres. ${ }^{20}$ "A saúde dos indivíduos e das populações são influenciadas por complexas forças sociais e estruturais. Dessa forma, enfrentar as raízes da enfermidade inclui combater a pobreza, a desigualdade e a degradação ambiental. Isso exige uma ampla agenda de mudança social". ${ }^{21}$

A saúde global não está restrita ao contexto exclusivo da assistência médica, mas inclui tudo aquilo que torna as pessoas vulneráveis às doenças e à morte precoce devido à falta de assistência médica. Inclui também relações internacionais, especialmente no aspecto econômico, que marginalizam populações, criando pobreza e opressão. Muitos estudos têm mostrado que o principal fator que torna as pessoas mais vulneráveis à enfermidade e à morte precoce não é uma patologia em si mesmo, mas a pobreza. ${ }^{22}$ Assim sendo, a saúde global não pode se isentar de enfrentar a pobreza e a suas causas. A bioética que se adentra nas questões de saúde global precisa seguir um caminho que coloque as estruturas socioeconômicas e heranças históricas, como as que são fruto do colonialismo, em análise para enfrentar a pobreza e a opressão em sua relação com as desigualdades em saúde. ${ }^{23}$

A pandemia de Covid-19 mostrou a fragilidade da saúde global e suas tremendas injustiças. Apesar da saúde global, quando vista como um conceito ou mesmo como uma disciplina, soar como algo distante e abstrato, pois pode levar a se pensar em algo utópico, seus desafios e impacto na vida das pessoas são reais e ocorrem na esfera local. Por exemplo, uma decisão econômica de um país com mais poder - que cria um protecionismo de mercado que

\footnotetext{
${ }^{19}$ ABDALLA, S. M.; OGNENIS, S., Key Concepts in Global Health, p. 7; LAST, J. M., Public Health, p. 112.

${ }^{20}$ FARMER, P.; YONG KIM, J. et al., Reimagining Global Health, p. 1-14.

${ }^{21}$ FARMER, P.; YONG KIM J. et al., Reimagining Global Health, p. 10

${ }^{22}$ COMISIÓN ECONÓMICA PARA AMÉRICA LATINA Y CARIBE, Panorama Social da América Latina 2017; WORLD BANK, The. World Development Indicators 2016; SUMNER A.; HOY, C.; ORTIZ-JUAREZ, E., Estimates of the impact of COVID-19 on global poverty, p. 2-14.

${ }^{23}$ CUNHA, T.; LORENZO, C., Bioética global na perspectiva da bioética crítica, p. 121.
} 
lhe dá prioridade na compra de insumos médicos - faz com que um país de baixa renda, já sofrendo com a escassez de seus recursos econômicos, não possa competir nesse mercado. Consequentemente, a população desse país fica desprovida da assistência à saúde de que necessita. ${ }^{24}$ Apesar de trágica, a pandemia de Covid-19 tornou-se uma oportunidade para repensarmos as relações e as estruturas que controlam o mundo, com impactos na vida e na saúde das pessoas que são totalmente desiguais, pois essas estruturas protegem uns poucos privilegiados e exacerbam o sofrimento do restante da população mundial. A relação entre o global e o local está aí, explicitada pela pandemia. A bioética, se deseja ser relevante para além de discussões acadêmicas teóricas, deve se voltar às questões e aos problemas concretos na vida das pessoas que brotam dessa relação que chamamos de saúde global.

\section{Bioética e equidade em saúde global a partir de baixo}

Quando estamos no campo da saúde global, há um fato que deve ser afirmado desde o início: a principal causa dos problemas de saúde, doenças e mortes prematuras é a pobreza. ${ }^{25}$ Há um círculo vicioso ${ }^{26}$ que começa com a injustiça e termina com a morte: pobreza não é um fenômeno natural, mas uma criação socioeconômica que torna as pessoas vulneráveis ao adoecimento. Uma vez doente, uma pessoa pobre não tem acesso aos cuidados médicos necessários para se recuperar. Isso leva a mais sofrimento, tornando-a ainda mais pobre e doente. Como resultado, o pobre morre por conta de um processo de negação de sua dignidade.

Dessa forma, uma perspectiva bioética a partir da realidade do pobre se faz necessária para romper o círculo vicioso responsável pela vulnerabilidade, que torna muitas pessoas vítimas dessa violência contra a sua dignidade. Essa perspectiva se dá a partir do locus social onde se encontram as vítimas dessa violência estrutural. É uma perspectiva a partir de baixo, da experiência dos

\footnotetext{
${ }^{24}$ EYAWO, O.; VIENS, A. M., Rethinking the Central Role of Equity in the Global Governance of Pandemic Response, p. 549-553.

${ }^{25}$ Existem muitos relatórios abrangentes com estudos mostrando a conexão entre pobreza e doença. Esses relatórios são promovidos por organizações como a OMS, as equipes de trabalho do Banco Mundial e The Lancet, e podem ser encontrados em seus sites. Veja também: HABIBOV, N.; AUCHYNNIKAVA, A.; LUO, R., Poverty Does Make Us Sick, p. 1-12.

${ }^{26}$ Daniels Norman et al. falam de um círculo em que a pobreza causa problemas de saúde que tornam as pessoas vulneráveis ainda mais pobres e, portanto, reduzem o estado de saúde. DANIELS, N. et. al., Health and Inequality, or Why Justice Is good for Our Health, p. 65-66.
} 
pobres, que coloca suas vozes no centro de nossa discussão e de nossas ações por meio de uma opção preferencial por ele ${ }^{27} \mathrm{em}$ saúde global.

Neste artigo, não entraremos na discussão teórica sobre a opção preferencial pelos pobres, como foi desenvolvida originalmente pela Teologia da Libertação, e sobre o seu uso em áreas para além da Teologia, como a saúde. ${ }^{28} \mathrm{O}$ objetivo é avançar nessa reflexão, mostrando a contribuição da opção preferencial pelos pobres para uma bioética orientada a enfrentar os desafios da saúde global. Nesse sentido, a bioética - considerando o global a partir dos problemas concretos na realidade local que afeta a vida dos pobres e dos oprimidos - tem na opção pelos pobres uma perspectiva ética que permite aos bioeticistas um engajamento com os oprimidos e sua realidade, a fim de escutar suas vozes, aprender com suas experiências e, assim, buscar caminhos e práticas coletivas capazes de quebrar o círculo vicioso: pobreza, vulnerabilidade, falta de assistência à saúde, morte prematura.

Apesar da área conhecida como saúde global ter se expandido muito nos últimos anos, ela não é o foco da grande maioria dos estudos em bioética. Nos EUA, onde a saúde global tem ganhado cada vez mais espaço, os bioeticistas ainda continuam mais ocupados com as questões clínicas e os conflitos entre profissionais de saúde e pacientes devido à autonomia dos pacientes e ao uso de novas tecnologias. ${ }^{29} \mathrm{~A}$ justiça, que é um dos princípios do mantra

${ }^{27}$ A opção preferencial pelos pobres é um princípio do ensino social católico, originado na Teologia da Libertação, que apareceu pela primeira vez em um documento oficial da Igreja Católica em 1987 (Sollicitudo Res Socialis, n. 39) escrito pelo Papa João Paulo II. Ele incorporou este princípio ao magistério oficial após anos de seu desenvolvimento pelos teólogos da libertação e bispos latino-americanos. Posteriormente, o Papa Francisco deu continuidade a essa tradição, enfatizando o significado da opção preferencial pelos pobres como uma opção da fé cristológica (Evangelii Gaudium, n. 198) e um imperativo ético (Laudato Si', n. 158). Embora a opção preferencial pelos pobres tenha sido amplamente aceita nos ciclos teológicos em todo o mundo, o entendimento da maioria desses ciclos, particularmente no hemisfério norte, assumiu mais um aspecto teórico-conceitual do que uma implicação prática, como uma forma de vida e uma perspectiva a partir da qual se vê o mundo e se orienta as ações em vista da justiça. O foco na implicação prática da opção pelos pobres está nos primeiros escritos sobre este princípio, que apenas expressou teologicamente uma experiência vivida por comunidades latino-americanas nas décadas de 1950, 60 e 70. Para entender esse processo, veja: MARTINS, A., "The Preferential Option for the Poor as an Existential Commitment" in MARTINS, A., The Cry of the Poor, p. 59-75.

${ }^{28}$ GUTIÉRREZ, G., The Option for the Poor Arises from Faith in Christ, p. 317-326; GROODY, D. G.; GUTIÉRREZ, G. (Orgs.)., The Preferential Option for the Poor beyond Theology.

${ }^{29}$ Paul Farmer é um dos acadêmicos e líderes em saúde global que apresenta essa crítica: FARMER, P., Pathologies of Power, p. 196-212. 
de Georgetown (autonomia, beneficência, não maleficência e justiça), ${ }^{30}$ é fortemente abordada como uma perspectiva individual em relação àqueles que têm acesso aos cuidados médicos. Isso diminui o aspecto social da justiça, limitando o princípio de justiça ao relacionamento entre dois indivíduos.

A saúde pública e a global tratam da justiça na atenção à saúde que incorpora a participação dos indivíduos no bem comum. A justiça que cria participação no bem comum é aquela que promove a construção e a manutenção coletiva que permite uma relação justa entre pessoas e um acesso igualitário aos direitos cívico-sociais. Isso significa que a justiça cria condições para que as pessoas participem do bem comum, como o atendimento à saúde através do qual um indivíduo (que busca atendimento) encontrará o outro (que cuida), e ambos terão uma relação justa para a promoção do bem-estar de todos os envolvidos.

No campo da saúde global, o foco na justiça social também corre o risco de ser tão enfatizado teoricamente que às vezes esquecemos do indivíduo, principalmente aquela pessoa humilde que vive em uma área empobrecida. Não é raro que iniciativas de saúde global sejam desenvolvidas em escritórios de países ricos, considerando a cultura ocidental, para serem implementadas em uma região de baixa renda com cultura e visão de mundo totalmente diferentes. A implementação de tais projetos é cheia de potenciais conflitos, extremamente frágil e susceptível ao fracasso. Por quê? Porque os "especialistas" ignoram o conhecimento das pessoas que vivem nas realidades que eles desejam servir. Frequentemente, esses especialistas em saúde global querem saber mais sobre a vida e a experiência local dos pobres do que os próprios pobres. ${ }^{31}$

A implementação da imensa maioria dos projetos em saúde global, nas realidades locais marcadas pela pobreza, tem uma abordagem de cima para baixo. Essa abordagem faz parte do mainstream internacional e é pouco questionada. ${ }^{32}$ Muitas organizações, universidades e projetos patrocinados por

\footnotetext{
${ }^{30}$ Sobre esses princípios e o que eles significam, veja: CAMPBELL, A. V., Bioethics, p. 44-47.

${ }^{31}$ Posso afirmar isso testemunhalmente como uma pessoa que tem estado em ambos os lados em diferentes momentos da minha vida.

${ }^{32}$ A bioeticista Jennifer P. Ruger, cujo foco de trabalho é ética em saúde pública e que desenvolveu a perspectiva que chama de "ética em saúde pública positiva", em um trabalho recente publicado no The American Journal of Bioethics, reflete sobre a pandemia e os desafios éticos em termos de governança nas ações globais de enfrentamento da pandemia. A sua proposta é para uma perspectiva ainda mais centralizada no topo para uma organização e controle de caráter mundial nas ações locais em saúde global. Sua perspectiva ignora qualquer possiblidade
} 
governos ou pelo setor privado usam essa abordagem de cima para baixo, com um controle centralizado no topo da pirâmide. Não se questiona as boas intenções desses projetos, mas sua eficácia e seu respeito ético pelas particularidades e autodeterminação das pessoas que visam servir. Esse é um problema que muitos começam a identificar. Por exemplo, em um congresso sobre os Desafios Éticos em Saúde Pública Global, realizado pelo Boston College, ${ }^{33}$ a maioria dos painéis apontava para o entendimento de que as ações de saúde global devem envolver as comunidades locais, valorizando seu conhecimento, cultura e experiências. Assim, as iniciativas globais de saúde promovem ações com parceiros locais para criar independência.

No entanto, uma abordagem que começa de baixo, dando voz às comunidades locais nos processos de tomada de decisão, está longe de ser adotada por algumas das principais organizações de saúde global, como a própria Organização Mundial da Saúde. Thana Cristina de Campos, da Pontifícia Universidade Católica do Chile, destaca que a centralização é a perspectiva dominante na governança da saúde global, com ações, projetos e sistemas controlados por um poder central como a OMS ou, mesmo em níveis mais elevados, como a própria Nações Unidas. Segundo Campos, a falta de objetivos comuns claros, de inclusão das comunidades locais e de coordenação são os principais problemas da governança em saúde global, reconhecidos até mesmo por aqueles que defendem a centralização. Na contramão da tendência, Campos defende uma governança em saúde global baseada no princípio de subsidiariedade. ${ }^{34}$ Este princípio - desenvolvido pelo ensino social católico e incluído no Tratado da União Europeia, artigo 5 - cria um caminho para uma governança em saúde global que inclui experiências e comunidades locais, empoderando e respeitando suas próprias particularidades. Isso ocorreria porque o princípio da subsidiariedade se assenta em três pilares: não-abandono, não-absorção e coordenação. Esses aspectos do princípio de

de contribuição efetiva nos processos de decisões das pessoas que sofrem na realidade local. RUGER, J. P., Positive Public Health Ethics, p. 44-45. Mas essa perspectiva de cima para baixo não passa despercebida e Thana C. de Campos a responde dizendo que esse tipo de modelo cria problemas para o contexto local, onde as ações são desenvolvidas, pois abre espaço para o estabelecimento de barreiras para a participação das comunidades locais nos processos de decisões. DE CAMPOS, T. C., Guiding Principles of Global Health Governance in Time of Pandemics, p. 212-214.

${ }_{33}$ BOSTON COLLEGE - The Schiller Institute for Integrated Science and Society, "Ethical Challenges in Global Public Health".

${ }^{34}$ DE CAMPOS, T. C., The Global Health Crisis, p. 219-260. 
subsidiariedade são mais apropriados para enfrentar os três principais desafios da governança em saúde global, porque favorecem que as comunidades sejam agentes de saúde global a partir de sua própria realidade, considerando sua visão de mundo e suas experiências. ${ }^{35}$

A sugestão de Campos de usar o princípio da subsidiariedade com um guia na governança de ações em saúde vai na mesma direção da perspectiva de promoção global da saúde baseada na opção preferencial pelos pobres. Essa opção direciona as iniciativas em saúde global para o envolvimento das comunidades locais, considerando o conhecimento de seus moradores e sua experiência em meio à pobreza. Portanto, os pobres tornam-se parceiros ativos em ações de saúde em suas comunidades e não apenas destinatários de ações de saúde global, oriundas de nações ricas e determinadas por líderes distantes da realidade local, onde os problemas são experienciados.

Considerando que questões de justiça e de participação no bem comum (seja no acesso a serviços médicos ou na governança de ações de saúde) são desafios éticos centrais na saúde global, a opção preferencial pelos pobres oferece uma perspectiva que inverte a abordagem mais comum dos cuidados de saúde, tornando os pobres e suas vozes parceiros centrais no esforço de promoção da saúde global. Uma perspectiva a partir dos pobres contribui para a quebra do círculo vicioso criado pelo empobrecimento (pobreza, vulnerabilidade, doença, falta de cuidados de saúde, morte prematura). É uma perspectiva a partir de baixo que respeita as particularidades das comunidades locais, fazendo com que as vozes dos pobres sejam escutadas e levadas a sério. Portanto, um pensar e agir a partir de baixo oferece um caminho inclusivo para responder a uma crítica comum de que as organizações de saúde global promovem uma nova forma de colonialismo, porque criam dependência e não trabalham para o empoderamento de comunidades empobrecidas e por seu desenvolvimento autônomo a partir de sua própria visão de mundo e capacidade de colaboração.

Ademais, a equidade na saúde global é uma questão ética porque, em seu centro, há uma questão de justiça: justiça social - nas estruturas e serviços

\footnotetext{
${ }^{35} \mathrm{Na}$ sua mais recente análise, Thana de Campos também inclui os princípios de solidariedade e stewardship como complementares ao princípio de subsidiariedade, como razões éticas para um "mandatado minimalista" que garanta "responsabilidades partilhadas" com comunidades e agentes globais. Os três princípios permitem uma comunicação entre agentes locais e globais de forma consistente e fundamentada em evidências, ao mesmo tempo que permite um controle de averiguação se a ação de cada agente está sendo responsável, isto é, sem desvios morais. DE CAMPOS, T. C., Guiding Principles of Global Health Governance in Time of Pandemics, p. 214.
} 
que criam acesso aos cuidados de saúde - e justiça na forma de lidar com as pessoas (locais), para que possam participar, com sua voz e conhecimento, nos processos de tomada de decisão. Esses são elementos essenciais para a justiça social e para um estado democrático, encontrados na opção pelos pobres e na metodologia que se constrói a partir desse princípio, e aliados na construção de ações inclusivas em saúde.

Aqui o Papa Francisco oferece uma contribuição relevante ao apresentar a opção preferencial pelos pobres como um imperativo ético para a "efetiva realização do bem comum". ${ }^{36}$ Apesar de ser um princípio oriundo da Teologia, essa opção tem um aspecto sociopragmático que une os dois aspectos de justiça mencionados, contribuindo, assim, para a equidade na saúde. Seguindo o que fala o médico antropologista e um dos líderes em saúde global, Paul Farmer, a opção preferencial pelos pobres sugere uma "solidariedade pragmática" ${ }^{37}$ que orienta: (1) iniciativas e sistemas de saúde com impactos estruturais públicos de caráter local e global - como programas de saúde pública que preenchem lacunas criadas por injustiças, dando aos pobres prioridade para contribuírem na equidade em saúde; (2) ações e interações locais que escutam os pobres nos processos de tomada de decisão e na promoção da saúde.

É necessário destacar que essa perspectiva a partir de baixo não exclui a contribuição técnica de profissionais da saúde, cientistas, acadêmicos e gestores, nem absolutiza a voz do pobre. O objetivo é criar um processo participativo-inclusivo a partir da realidade onde as injustiças em saúde são sentidas. Focando na justiça em saúde com os pés na realidade local, a opção preferencial pelos pobres nos leva a criar um processo de aprendizagem mútuo $^{38}$ entre a experiência dos pobres e o conhecimento técnico dos profissionais e promotores de saúde global. Por fim, para que esse processo se inicie, torna-se necessário estar com os pobres em um movimento de compaixão que os escuta, a fim de compreender seu sofrimento e sua realidade. Na companhia dos pobres,${ }^{39}$ escuta-se novas vozes que mostram uma experiência concreta entre sofrimento, lutas e esperança. Essas vozes também revelam a criatividade dos pobres juntamente com uma visão particular sobre os desafios em saúde que nenhuma abordagem de cima para baixo consegue abarcar. Engajar-se com eles é uma forma de criar um

\footnotetext{
${ }^{36}$ LS 158.

${ }^{37}$ FARMER, P., Pathologies of Power, p. 26.

${ }^{38}$ MARTINS, A. A., The Cry of the Poor, p. 214-216.

${ }^{39}$ FARMER, P.; GUTIÉRREZ, G., In the company of the poor.
} 
processo de transformação com colaboração mútua. Em um trabalho onde o conceito de aprendizagem mútua é desenvolvido a partir de experiências de trabalho com os pobres, o autor afirma: "As vozes dos pobres nos dirão o que significam seu sofrimento e luta, e nos ajudarão a moldar ações coletivas capazes de responder os desafios da desigualdade social e de saúde, sem uma destruição antropológica". ${ }^{40}$

\section{Conclusão}

O debate sobre uma bioética global, centrado na legitimidade ou não de princípio universais, corre o risco de limitar o aspecto global da bioética, restringindo-a a si mesma e isentando-a do enfrentamento das questões de saúde global com impacto direto na vida das pessoas em sua realidade local. Dessa forma, a proposta apresentada aqui não marginaliza a busca por uma bioética global, entendida como uma reflexão de caráter universal, mas enfatiza a necessidade de uma bioética orientada para enfrentar as questões de saúde global a partir da realidade local, e no engajamento com as pessoas que sentem o impacto das injustiças em saúde diretamente em suas vidas; isto é, uma bioética a partir de baixo na qual os pobres, oprimidos e marginalizados possam ser incluídos na reflexão bioética e nos processos de decisões em saúde global. Para incluir os pobres e suas vozes no bem comum, a bioética e a saúde global têm muito a aprender com as perspectivas que começam com iniciativas em comunidades locais, fortalecendo suas experiências e apoiando o protagonismo das pessoas dessas comunidades. A inclusão de uma perspectiva ética a partir de baixo na agenda de ações da saúde global, e das questões éticas oriundas dessas ações na discussão bioética, contribuirá para o desenvolvimento dessas duas áreas, unidas pela subdisciplina bioética e saúde global.

\section{Referências bibliográficas}

ABDALLA, S. M.; OGNENIS, S. Key Concepts in Global Health. In: SETHIA, B.; KUMAR, P. (Orgs.). Essentials of Global Health. Polonia: Elsevier, 2019. p. 7-13.

ANJOS, M. F. dos. Bioética em perspectiva de libertação. In: GARRAFA, V;

${ }^{40}$ MARTINS, A. A., The Cry of the Poor, p. 128. 
PESSINI, L. (Orgs.). Bioética: poder e injustiça. São Paulo: Loyola, 2003. p. 455-465.

BARCHIFONTAINE, C. P. Saúde pública é bioética? São Paulo: Paulus / Centro Universitário São Camilo Press, 2005.

BARCHIFONTAINE, C. P. ; ZOBOLI, E. (Orgs.). Bioética, vulnerabilidade e saúde. São Paulo: Centro Universitário São Camilo Press, 2007.

BOFF, L. Jesus Cristo libertador: ensaio de cristologia crítica para o nosso tempo. Petrópolis: Vozes, 2012.

BOSTON COLLEGE - The Schiller Institute for Integrated Science and Society. Ethical Challenges in Global Public Health, 16 set. 2019. Disponível em: $<$ www.bc.edu/bc-web/academics/sites/ila/events/Ethical-changes-publichealth.html\#about_the_conference>. Acesso em: 23 fev. 2021.

CAMPBELL, A. V. Bioethics: The Basics. New York: Routledge, 2017.

COMISIÓN ECONÓMICA PARA AMÉRICA LATINA Y CARIBE. Panorama Social da América Latina 2017. Santiago: Naciones Unidas Press, 2017.

CUNHA, T.; GARRAFA, V. Vulnerability: A key Principle for Global Bioethics? Cambridge Quartely of Healthcare Ethics, v. 25, n. 2, p. 197-208, Apr. 2016. Disponível em: <https://doi.org/10.1017/S096318011500050X>. Acesso em: 16. fev. 2021.

CUNHA, T.; LORENZO, C. Bioética global na perspectiva da bioética crítica. Revista bioética, v. 22, n. 1, p. 116-125, jan./abr. 2014. <https://doi. org/10.1590/S1983-80422014000100013>. Acesso em: 10 mar. 2021.

DANIELS, N. at al. Health and Inequality, or Why Justice Is good for Our Health. In: ANAND, S.; PETER, F.; SEN A. (Orgs.). Public Health, Ethics, and Equity. New York: Oxford University Press, 2004. p. 63-102.

DE CAMPOS, T. C. Guiding Principles of Global Health Governance in Time of Pandemics: Solidarity, Subsidiarity and Stewardship in COVID-19. The American Journal of Bioethics, v. 20, n. 7, p. 212-214, jul. 2020. Disponível em: <https://doi.org/10.1080/15265161.2020.1779862>. Acesso em: 10 mar. 2021.

DE CAMPOS, T. C. The Global Health Crisis: Ethical Responsibilities. Cambridge: Cambridge University Press, 2017. 
ENGELHARDT, H. T. Global Bioethics: An Introduction to the Collapse of Consensus. in: ENGELHARDT, H. T. (Org.). Global Bioethics: The Collapse of Consensus. Salem, MA.: M\&M Scrivener Press, 2006. p. 1-17.

EYAWO, O.; VIENS, A. M. Rethinking the Central Role of Equity in the Global Governance of Pandemic Response. Bioethical Inquiry, v. 17, p. 549553, ago. 2020. Disponível em: <https://doi.org/10.1007/s11673-020-100012>. Acesso em: 10 mar. 2021.

FARMER, P. Pathologies of Power: Health, Human Rights, and the New War on the Poor. Berkeley: University of California Press, 2003

FARMER, P. Patologias do poder: saúde, direitos humanos e a nova guerra contra os pobres. São Paulo: Paulus, 2018.

FARMER, P.; GUTIÉRREZ, G. In the company of the poor: conversations with Dr. Paul Farmer and Fr. Gustavo Gutiérrez. Maryknoll, NY.: Orbis Books, 2013.

FARMER, P.; YONG KIM, J. et al. Reimagining Global Health: An Introduction. Berkeley, London: University of California Press, 2013.

FORTES, P. A. de C. Refletindo sobre os valores éticos da saúde global. Saúde e Sociedade, v. 24, n. 1, p. 152, 162, abr.jun., 2005. Disponível em: <http://dx.doi.org/10.1590/S0104-12902015S01013>. Acesso em: 10 mar. 2021.

FORTES, P. A. de C.; ZOBOLI, E. L. (Orgs.). Bioética e saúde pública. São Paulo: Edições Loyola, 2003.

FRANCISCO, papa. Carta encíclica Laudato si', 24 mai. 2015. Disponível em: $<$ http://www.vatican.va/content/francesco/pt/encyclicals/documents/papafrancesco_20150524_enciclica-laudato-si.html>. Acesso: 16 fev. 2021.

GARRAFA, V.; PORTO, D. Bioética, poder e injustiça: por uma ética da intervenção. In: GARRAFA, V; PESSINI, L. (Orgs.). Bioética: poder e injustiça. São Paulo: Loyola, 2003. p. 37-45.

GroOdY, D. G.; GUTIÉRREZ, G. (Orgs.). The Preferential Option for the Poor beyond Theology. Notre Dame: University of Notre Dame Press, 2013. GUTIÉRREZ, G. The Option for the Poor Arises from Faith in Christ. Theological Studies, v. 70, n. 2, p. 317-326, 2009.

HABIBOV, N.; AUCHYNNIKAVA, A.; LUO, R. Poverty Does Make Us 
Sick. Annals of Global Health, v. 85, n. 1, p. 1-12, mar. 2019. Disponível em: <https://doi.org/10.5334/aogh.2357>. Acesso em: 10 mar. 2021.

JESUS, R. A. de; MEDINA, M. G.; PRADO, N. M. de B. L. Programa Mais Médicos: análise documental dos eventos críticos e posicionamento dos atores sociai. Interface, v. 21, suppl.1, p. 1241-1256, 2017. Disponível em: $<$ https:// doi.org/10.1590/1807-57622016.0555 >. Acesso em: 10 mar. 2021.

LAST, J. M. Public Health. In: LAST, J. M. (Org.). A Dictionary of Public Health. New York: Oxford University Press, 2007.

LYSAUGHT, M. T.; McCarthy, M. (Orgs.). Catholic Bioethics \& Social Justice: The Praxis of US Health Care in a Globalized World. Collegeville, MN: Liturgical Press, 2019.

MARTINS, A. A. The Cry of Poor: Liberation ethics and justice in health care. Lanham, MD.: Lexington Books, 2020.

NOHAMA, N.; DA SILVA, J. S.; SIMÃO-SILVA, D. Desafios e conflitos bioéticos da covid-19: contexto da saúde global. Revista Bioética, v. 28, n. 4, p. 585-594, Oct./Dec. 2020. <http://dx.doi.org/10.1590/198380422020284421>. Acesso em: 10 mar. 2021.

PESSINI, L. Bioética global, vulnerabilidade e agenda 2030 da ONU. In: MILLEN, M. I. C.; ZACHARIAS, R. Ética teológica e direitos humanos. Aparecida: Santuário / SBTM, 2018. p. 401-446.

RUGER, J. P. Positive Public Health Ethics: Toward Flourishing and Resilient Communities and Individuals. The American Journal of Bioethics, v. 20, $\mathrm{n}$. 7, p. 44-45, jun. 2020. Disponível em: <https://doi.org/10.1080/15265161.20 20.1764145>. Acesso em: 10 mar. 2021.

SUMNER A.; HOY, C.; ORTIZ-JUAREZ, E. Estimates of the impact of COVID-19 on global poverty. WIDER Working Paper, n. 43, p. 2-14, abr. 2020. Disponível em: <https://doi.org/10.35188/UNU-WIDER/2020/800-9>. Acesso em: 10 mar. 2021.

TEN HAVE, H. Global Bioethics: An Introduction. New York: Routledge, 2016.

THE AMERICAN JOURNAL OF BIOETHICS, v. 20, n. 7, jun. 2020.

UNESCO. Declaração Universal sobre Bioética e Direitos Humanos, 2006.

Disponível em: <https://unesdoc.unesco.org/ark:/48223/pf0000146180>. Acesso em: 16 fev. 2021. 
WORLD BANK, The. World Development Indicators 2016: Featuring the Sustainable Development Goals. Washington, DC.: The World Bank Press, 2016.

Alexandre Andrade Martins

Doutor em Ética Teológica e Bioética pela Universidade Marquette Docente no Departamento de Teologia e na Escola de Enfermagem da

Universidade Marquette

Milwaukee / WI - EUA

E-mail: alexandre.martins@marquette.edu

Recebido em: 10/03/21

Aprovado em: 16/06/21 